\title{
MS VAT. SYR. 268 AND THE REVISIONAL DEVELOPMENT OF THE HARKLEAN MARGIN
}

\author{
ANDREAS JUCKEL \\ INSTITUT FÜR NEUTESTAMENTLICHE TEXTFORSCHUNG \\ UNIVERSITY OF MÜNSTER
}

\section{INTRODUCTION $^{\dagger}$}

When R. Köbert in 1975 published his short article ${ }^{1}$ on Ms Vat. syr. 268 , his primary concern was to provide scholars with a guide to this manuscript by giving an analysis of its content folio-by-folio. This was made necessary due to a careless (re)binding of the manuscript (before pagination) which put the folios into disorder. The background of Köbert's article was his co-operation with the

$\dagger$ vSod $=$ Hermann Freiherr von Soden, ed., Die Schriften des Neuen Testaments in ibrer ältesten erreichbaren Textgestalt hergestellt auf Grund ibrer Textgeschichte, I. Teil: Untersuchungen (Göttingen, 1911); II. Teil: Text und Apparat (Göttingen, 1913). - IGNTP = The New Testament in Greek. The Gospel according to St. Luke, ed. by the American and British committees of the International Greek New Testament Project. Part I (chapters 1-12) (Oxford, 1984), Part II (chapters 13-24) (Oxford, 1987). - NA27 = B. Aland, K. Aland, J. Karavidopoulos, C. Martini and B. Metzger (eds.), Novum Testamentum graece (Stuttgart, 199327). - Syn = K. Aland (ed.), Synopsis quattuor evangeliorum (Stuttgart, 199616). - CESG = George A. Kiraz (ed.), Comparative Edition of the Syriac Gospels. Aligning the Sinaiticus, Curetonianus, Peshitta \& Harklean Versions, vol. I-IV (Leiden, 1996).

${ }^{1}$ Biblica 56 (1975): 247-50. 
International Greek New Testament Project (Luke, vol. I, 1984; vol. II, 1987). Supplying the editor(s) with the readings of the Harklean version, he relied not only on the editio princeps of $\mathrm{J}$. White ${ }^{2}$ (Gospels 1778), but also on Vat. syr. 267 and 268 of the $8^{\text {th }} / 9^{\text {th }}$ century. No doubt he was right in using manuscripts dating from the first millennium for quoting the Harklean evidence. But he certainly

did not use the Vatican manuscripts simply to confirm White's text (founded principally on a single late manuscript, i.e. New College 333, Oxford) by tracing its readings back to the first millennium. Many of the divergent Vatican readings can easily put into question the originality of White's text by their age and common agreement against it. Obviously Köbert's intention was to enlarge the horizon of the Harklean evidence and to escape from the idiosyncrasies of a single manuscript, i.e. White's edition. We are not told if Köbert realized the revisional development within the Harklean tradition which is the clue to understand the variations of the Harklean text and margin. In any case he was the first to introduce Harklean readings taken from early Harklean manuscripts into a scholarly edition of the Greek New Testament, thus opposing-intentionally or not-the unprooved assumption - that White's text is a reliable source for the original Harklean. ${ }^{3}$

The general purpose of the present article is to continue Köbert's effort to promote our knowledge of the early Harklean text and to move towards a critical edition of the Harklean Gospels based on the manuscripts of the first millennium. ${ }^{4}$ The special

2 Sacrorum Evangeliorum versio Syriaca Philoxeniana ex codd. mss. Ridleianis nunc primum edita cum interpretatione et annotationibus, tomus I (Oxonii, 1778).

3 Though a rare set of volumes, the influence of White's text was (and still is) primarily granted by the scholarly Greek editions which present(ed) its readings as being taken from the original seventh-century version itself, e.g. in the editions of Tischendorf, von Soden, Nestle, Nestle-Aland (GNT). White's solid achievement did not lose admiration when in the course of time it became clear that the text he published was neither the Philoxenian (as he claimed in the title) nor the original Harklean produced by Thomas of Harqel in 615/16. What he published is actually a revision of the Harklean, clearly distinct from the text we meet in the manuscripts of the first millennium, see CESG, vol. I, p. xxxix.

4 The Letters of St. Paul in the Harklean version are edited by B. Aland and A. Juckel, Das Neue Testament in Syrischer Überlieferung, vol. II,1 
purpose of this article, however, is to prove the importance of Vat. syr. 268 in establishing the original text and for gaining an understanding of the text's early revisional development. It will also give an idea about the reason why this manuscript was chosen to be published in the Comparative Edition of George A. Kiraz. ${ }^{5}$ It is confined to the study of the Harklean margin which is the characteristic feature of this version and especially suitable for tracing revisional development. For convenience the readings of the textline and the margin are presented in Greek, the Syriac form can easily be traced in the Comparative Edition vol. I (p. lii-lxxxii the marginal readings).

\section{THE HARKLEAN APPARATUS}

The Harklean Tetraevangelium is a literal translation of a Greek model prepared in 615/16 by Thomas of Harqel (Heraklea in the Euphratensis), bishop of Mabbug, when he was in exile near Alexandria. From the general subscription to the Gospels we learn that Thomas actually proceeded by revising the Philoxenian version of 507/8 with the help of two or three Greek manuscripts representing the graeca veritas for him. The procedure resulted in a scholarly edition including an apparatus ${ }^{6}$ with variant readings of the Greek and Syriac tradition (the former translated into Syriac) in the margin, and critically (with asterisks and obeli) marked words and passages in the text. Numerous Greek words in the margin are quoted to give the exact Greek background of single words or expressions in the Harklean text; they are not variant readings

(Rom and 1 Cor, 1991), II,2 (2 Cor - Col, 1995), II,3 (1 Thess - Hebr, forthcoming).

${ }^{5}$ According to the principal aim to keep to the comparative purpose of the CESG, no philological edition in the proper sense nor extensive collations of other Harklean manuscripts (e.g., of Ms Vat. syr. 267 and of White's text) could be printed. But Kiraz allowed a lengthy introduction to the Harklean text giving a description of the complex physiognomy of this version and an outline of its revisional development. For general information concerning the subject of this article the reader is referred to this introduction.

6 The Harklean apparatus was studied by John D. Thomas, The Harklean margin. A study of the Asterisks, Obeli, and Marginalia of the Harklean Syriac version with special reference to the Gospel of Luke. Ph. Diss., St. Andrews (Franklin, Pa., 1973). 
opposed to the Harklean textline. The purpose of the apparatus was to include textual material current in Thomas' time to serve scholarly discussion, thus 'translating' the essential Greek textual tradition, not just a single manuscript as happened in the time of Philoxenus.

This apparatus is the characteristic feature of the Harklean; nevertheless, in most of the manuscripts it is omitted by the scribes. From the first millennium there are only four principal manuscripts attesting the Harklean apparatus: Mss Vat. syr. 267 (ca. $8^{\text {th }} c$.) and 268 ( $c a .8^{\text {th }} / 9^{\text {th }} c$.), Ms Mingana syr. 124 (Mingana: "about A.D. 730 ") all of them with defects of their own, and Ms syr. 703 of the Chester Beatty Library (Dublin) which is from the beginning of the second millennium (1177 A.D.) but may be added here, because it was copied from a model dated 841 A.D. ${ }^{7}$ Two more manuscripts (Ms British Library Add. 7163 , ca. $9^{\text {th }} / 10^{\text {th }}$ century; Ms Harvard syr. $16, c a .8^{\text {th }} / 9^{\text {th }}$ century) are fragmentary.Poor attestation of the Harklean apparatus, mutilation, susceptibility to incorrect copying due to its complexity, and finally revisional alteration are severe obstacles to reaching its original form. To enlarge the attestation by turning to manuscripts of the second millennium (the principal manuscript is New Coll. 333 edited by J. White) would not be a reliable contribution to our knowledge of the original apparatus. At the beginning of the second millennium revisional development of the Harklean was reinforced by Dionysius Bar Salibi (+ 1171), bishop of Amid (Diyarbakir), who reorganized the apparatus considerably and influenced the Harklean tradition of the times to follow. Therefore it is a matter of method to confine research on the original Harklean apparatus to manuscripts of the first millennium.

\section{THE REVISIONAL DEVELOPMENT TOWARDS THE BYZANTINE TEXT}

The revisional alteration we meet in the four manuscripts of the first millennium is indicated 1) by the fact that there is an exchange of reading between textline and margin, i.e. what is in the textline of one manuscript is in the margin of the other, and vice versa; 2 ) by

7 A note in the manuscript tells us that the model itself was collated with the correct codex of Qurisuna, probably a revised Harklean codex of great esteem. 
the different use of the critical signs (asterisks and obeli); 3) by numerous variant readings of the textline due to variants known from the Greek tradition, or giving a different rendering of the homogeneous Greek text. We cannot believe the scribes to be capable of these alterations which were made after renewed consultation of the Greek text; and so we have to ascribe them rather to malphone who were concerned with the correctness and reliability of the Harklean text and were familiar with Greek. In the four manuscripts used for this article we basically find the same text and margin, slightly but significantly altered. Compared with the thorough revision undertaken by Dionysius Bar Salibi, not the whole is shifted but only parts of it. This is important for claiming that the common textual substance of our four manuscripts depends on the original Harklean and that the revisional development gradually grew out of the tradition itself, and was not imposed by a single individual. ${ }^{8}$

In CESG, vol. I, p. xxxvii the revisional development of the Harklean is said to be generally connected with the development of the Greek text towards the uniform and then dominant Byzantine text (majority text). This is especially true with regard to the revisional alteration of the apparatus in the early Harklean manuscripts. For a great number of these alterations are promoting the Byzantine text by removing the non-Byzantine reading of the textline to the margin or even by eliminating it. The importance of Ms Vat. syr. 268 for our knowledge of the early revisional development is the fact that it maintains many non-Byzantine readings which the other three manuscripts revise in favour of the Byzantine text. To demonstrate the shifting of the early Harklean text towards the Byzantine text some lists of readings are given below. The conclusion that will be drawn from them is that Ms Vat. syr. 268 does in fact represent an earlier stage of revision than the other three manuscripts used in this article and a critical edition of the Harklean Gospels should principally rely on this manuscript.

8 That is what Dionysius Bar Salibi in the $12^{\text {th }}$ century did. His revision surely relied on revised Harklean manuscripts and started a new period within the Harklean revisional development, see CESG, vol. I, p. xxxvii-xxxix. 


\section{LIMITATIONS}

a) The first limitation is the choice of the four manuscripts mentioned before. They are in fact the principal ones ${ }^{9}$ of the first millennium representing the Harklean apparatus. The defect of Ms Vat. syr. 268 is the damage of its text and margin especially in St. John's Gospel. But even when the marginal reading is lost, the fact of its existence is recorded by the word in the textline which preserves the graphic sign referring to the margin. ${ }^{10}$ This is also true for Ms Mingana syr. 124, most of whose marginalia must be inferred from the reference in the textline and from the intact margin of the other three manuscripts. To improve the reliability, Ms Plut. I.40 of the Biblioteca Laurenziana was used to confirm the non-Byzantine textline reading of the Vatican manuscript. This manuscript (no apparatus, dated 756 A.D. and certainly older than Ms Vat. syr. 268) is in agreement with Ms Vat. syr. 268 in the lists $\mathrm{A}$ and $\mathrm{B}$ below, but according to list $\mathrm{C}$ it is affected by revisional alteration.

b) All evidence presented in the lists below is taken from the Harklean margin of Luke. In this Gospel, which is the longest one, we find the most extensive apparatus, and here the damage of the manuscripts just mentioned hardly affects the evidence. It was in the apparatus where Thomas of Harqel quoted or marked variant readings of the Greek and Syriac tradition known to him. Again it is the apparatus where the revisors of the Harklean are quoting or marking non-Byzantine readings formerly belonging to the Harklean textline itself, thus correcting the Harklean. This shifting purpose of the apparatus, from quoting to correcting, can be traced best with the marginal readings, but not with the words put with critical signs in the text. The asterisks and obeli are rather inconsistently transmitted in the manuscripts, and thus have textcritical problems of their own. ${ }^{11}$ So this (admittedly essential)

${ }^{9}$ For the Vatican manuscripts and Ms syr. 703 of the Chester Beatty Library (Dublin) see CESG, vol. I, p. xlv-xlix. Ms Mingana syr. 124 is described by A. Mingana, Catalogue of the Mingana Collection of Manuscripts, vol. I (Cambridge, 1933) 290-3.

${ }^{10}$ In CESG the illegible marginal readings of Ms Vat. syr. 268 are supplemented by the help of Ms Vat. syr. 267 in the list of the marginal readings p. lii-lxxxii.

${ }^{11}$ What is true for the marginal readings we surely will have to accept for the words and passages marked with critical signs: not all of them 
part of the Harklean apparatus is neglected in the present article. But for the purpose of this paper, it is sufficient to confine all evidence presented in the lists below to the marginal readings and to the word(s) in the textline referring to the margin. The purpose of list $A$ is to show that the original Harklean Gospels were principally founded upon the (early) Byzantine text. List $B$ will give the divided attestation of the margin of Ms Vat. syr. 268, i.e. the revisional alteration of the Harklean margin. List $C$ gives nonByzantine readings of the textline in Ms Vat. syr. 268 which were removed to the margin of the three other manuscripts by the activity of revisors, i.e. the revisional alteration of the text.

\section{LISTS OF READINGS}

\section{List A}

List A aims to show that the original Harklean Gospel text depends on an early version of the Byzantine text. This recension of the Greek text can be traced back to the fourth century and is the dominant and then uniform text ${ }^{12}$ of the Byzantine Empire, approved by ecclesiastical and secular authorities. Its earlier version was less uniform than in later times, and the variety of the earlier version is present in the Harklean manuscripts in a number of "old" readings which were later regarded as non-Byzantine and sufficient enough by number to provoke their revisional elimination. The Greek manuscripts chosen by Thomas might have belonged to the $5^{\text {th }} / 6^{\text {th }}$ century. His intention obviously was to bring the Philoxenian in line with the generally accepted Greek text, quoting its variety in the margin. We can imagine him proceeding by relying principally on a "normal good" Greek manuscript, compiling the apparatus out of variant readings taken from one or two additional manuscripts (and the Philoxenian?). It is unlikely that Thomas' intention was to promote or reject special

derive from Thomas of Harqel himself but partly from revisors of the Harklean. Especially those combined with a textcritical comment in the margin might be due to the revisors, see Lk 6,1 8,24.52 9,23.50 19,38.45.

${ }^{12} \mathrm{H}$. von Soden treats the early stage and the development of the Byzantine text (Koiné) in Die Schriften des Neuen Testaments, vol. I,2 (Göttingen) 712-65. On page 708 v. Soden says: "Dagegen [i.e. compared with the pre-Byzantine text] hat $K$ [i.e. the Koiné] ohne Aufhören als Korrektiv gedient für die von ihm abweichenden Texte". 
selected readings. He was a translator (revisor) rather than a critic. What today seems to be the fruit of his textcritical judgement is probably due to the limitation of the material he was relying on. The basic foundation of the original Harklean Gospels on the Byzantine text is not a surprising fact, for it was the text of dominant influence and regarded as superior in style and "correctness" to all remnants of texts prior to or contemporary with the Byzantine. Only a revision of the Philoxenian according to this text could really serve scholarly and dogmatic discussion ${ }^{13}$ for centuries, being the final revision of the Syriac New Testament not only for the extent of its "mirroring" the Greek model, but also for being founded upon the text of the future. Due to the gradual advance of the Greek text behind the Harklean Gospels towards uniformity the need for control, comments and revision is evident. Only by revisional dependence on the shifting Greek text could Thomas' intention be maintained: to keep the Syriac New Testament in line with the current Greek text. Only this allowed the Harklean to remain a useful instrument for scholarly research.

In this first list the four manuscripts used in this article have the same (Byzantine) reading in the textline, and there are no differences in the margin. Since the following readings are all present in the Nestle-Aland ${ }^{27}$ edition, their Greek support for the text and the margin is not listed here. The Harklean text and margin of this list is in agreement with White's edition. As the Greek background is concerned, all readings are given in Greek, the original Syriac text (and the marginal readings) can be looked up in CESG, vol. I, p. lxvi-lxxvi.

- 2,9 Hkxt kupiou, Hkmg $\theta \varepsilon o u-2,33$ Hkæx o I $\omega \sigma \eta \phi$, Hkmg

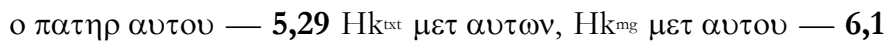
Hk ${ }^{\mathrm{xt}} \varepsilon v \sigma \alpha \beta \beta \alpha \tau \omega \delta \varepsilon v \tau \varepsilon \rho \circ \pi \rho \omega \tau \omega$, Hkmg OM. $\delta \varepsilon v \tau \varepsilon \rho о \pi \rho \omega \tau \omega-$

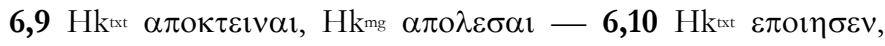
Hkmg $\varepsilon \xi \varepsilon \varepsilon \varepsilon i v \varepsilon v-7,1 \mathrm{Hk}$ xx $\varepsilon \pi \varepsilon 1 \delta \eta \varepsilon \pi \lambda \eta \rho \omega \sigma \varepsilon v$... $\varepsilon 1 \sigma \eta \lambda \theta \varepsilon v, \mathrm{Hk}^{\mathrm{mg}}$

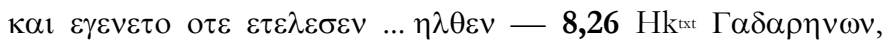

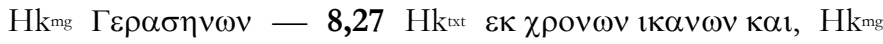

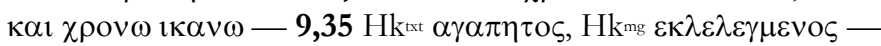
9,49 $\mathrm{Hk}^{\text {xx }} \varepsilon \pi \iota \sigma \tau \alpha \tau \alpha, \mathrm{Hk}^{\mathrm{mg}} \delta \iota \delta \alpha \sigma \kappa \alpha \lambda \varepsilon-10,19 \mathrm{Hk}^{\text {st }} \delta \iota \delta \omega \mu \mathrm{l}, \mathrm{Hk}^{\mathrm{mg}}$

13 There is an interesting "guess" of G. Zuntz, that the Harklean edition ultimately was undertaken to serve the reunion of the Syrian Orthodox (Miaphysite) party of Thomas and the (Greek) Orthodox, see Ancestry of the Harklean New Testament (London, 1945) 11-2. 


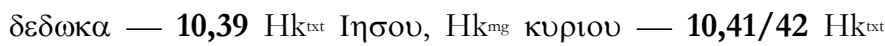

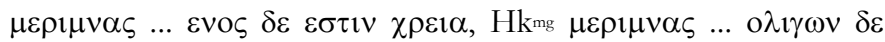
$\varepsilon \sigma \tau \iota v \chi \rho \varepsilon 1 \alpha \eta \varepsilon v o \varsigma-17,23 \mathrm{Hk}^{\mathrm{txt}} \mu \eta \alpha \pi \varepsilon \lambda \theta \eta \tau \varepsilon \mu \eta \delta \varepsilon \delta 1 \omega \xi \eta \tau \varepsilon$, $\mathrm{Hk}^{\mathrm{mg}} \mu \eta \pi \mathrm{l} \sigma \varepsilon v \sigma \eta \tau \varepsilon-18,28 \mathrm{Hk}^{\mathrm{kxt}} \alpha \phi \eta \kappa \alpha \mu \varepsilon v \pi \alpha \nu \tau \alpha \kappa \alpha \mathrm{l}, \mathrm{Hk}^{\mathrm{mg}}$ $\alpha \phi \varepsilon v \tau \varepsilon \varsigma \tau \alpha \quad \delta 1 \alpha-20,33 \mathrm{Hk}^{\mathrm{xxt}} \varepsilon v \tau \eta$ ouv $\alpha v \alpha \sigma \tau \alpha \sigma \varepsilon 1, \mathrm{Hk}^{\mathrm{mg}} \eta$ $\gamma u v \eta$ ouv $\varepsilon v \tau \eta \alpha v \alpha \sigma \tau \alpha \sigma \varepsilon 1-20,34 \mathrm{Hk}^{\mathrm{txt}}$ SINE ADD. before

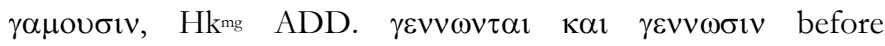

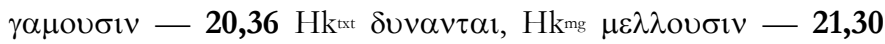
$\mathrm{Hk}^{\mathrm{xxt}} \eta \delta \eta, \beta \lambda \varepsilon \pi \mathrm{ov} \tau \varepsilon \varsigma \alpha \phi \varepsilon \alpha \nu \tau \omega \nu, \mathrm{Hk}^{\mathrm{mg}} \tau \mathrm{ov} \kappa \alpha \rho \pi \mathrm{ov} \alpha \nu \tau \omega \nu-$ 22,16 $\mathrm{Hk}^{\mathrm{txt}} \varepsilon \xi \alpha \nu \tau \mathrm{ov}, \mathrm{Hk}^{\mathrm{mg}} \alpha \nu \tau \mathrm{o}-23,33 \mathrm{Hk}^{\mathrm{txt}} \alpha \pi \eta \lambda \theta \mathrm{ov}, \mathrm{Hk}^{\mathrm{mg}}$

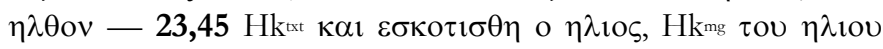
$\varepsilon \kappa \lambda \imath \pi \mathrm{ov} \tau \mathrm{os}$.

- The opposite case that the Byzantine text is in the Harklean margin we find in $3,8 \mathrm{Hk}^{\mathrm{xx}} \kappa \alpha \rho \pi \mathrm{ov} \alpha \xi \mathrm{lov}, \mathrm{Hk}^{\mathrm{mg}} \kappa \alpha \rho \pi \mathrm{ou} \varsigma$

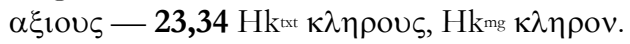

\section{List B}

[11] List B presents the divided attestation of the margin in the manuscripts (with identical textline throughout) and gives an impression of the difficulty in reconstructing the original margin. To ascribe the omission of marginalia generally to negligent scribes is not tenable: too many of them are omitted which is in contrast to the carefully written codices and to their actual proper attachment to the textline. And the possibility of accidental omission is reduced to the minimum by the way of attaching the whole apparatus: it probably was attached to the main text by a separate procedure, thus the marginalia were protected to a large extent from being dropped. But even if one prefers to blame the scribes for omitting the marginalia, the fuller margin of Ms Vat. syr. 268 would speak in favour of its priority. ${ }^{14}$

[12] A better understanding of the omissions comes from ascribing them to revisional activity. As long as the (non-Byzantine) marginalia could be identified within the Greek tradition availiable to the revisor(s) it was justified to maintain them. If identification

14 There are some marginalia of Ms Vat. syr. 268 which are not attested in the three other manuscripts at all: see 7,40 8,37.41 9,10.22 13,15.27 14,12 22,57 24,24. They are all non-Byzantine, the underlined ones probably variants due to translation technique. Theoretically it is possible that all these marginalia were removed from the text, thus Ms Vat. syr. 268 itself being affected by revisional activity. 
was not possible (for whatever reason) they could easily be regarded as out of use and not serving their original purpose any more. Accordingly, it seemed appropriate to omit them. The renewed consultation of Greek manuscripts by the revisor(s) to check the marginalia is beyond our control. Since some of the nonByzantine marginal readings of list B have only small support among the extant Greek witnesses, the reviser(s) might well not have come across them.

In this list the four manuscripts used for this article again have the same Byzantine reading in the textline. The non-Byzantine reading of V268 is in the margin, but omitted at least by one of the manuscripts. The Florentine manuscript (no apparatus) is confirming the textline throughout. V267, V268 = Ms Vat. syr 267, 268; $\mathbf{M}=$ Ms Mingana syr. 124; $\mathbf{D}=$ Ms Chester Beatty 703; $\mathbf{F}=$ Ms Plut. I.40, Florenz.

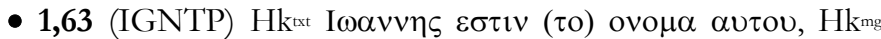
$\varepsilon \sigma \tau \alpha 1$ (not in D) - 1,78 (NA $\left.{ }^{27}\right) \mathrm{Hk}^{\mathrm{xt}} \varepsilon \pi \varepsilon \sigma \kappa \varepsilon \psi \alpha \tau \mathrm{O}, \mathrm{Hk}^{\mathrm{mg}}$ $\varepsilon \pi \imath \sigma \kappa \varepsilon \psi \varepsilon \tau \alpha \imath$ (not in D) - 2,21 (IGNTP) Hk ${ }^{\mathrm{xxt}} \eta \mu \varepsilon \rho \alpha \imath$, Hk $\mathrm{k}^{\mathrm{mg}}$ ADD. $\alpha$ (not in MD) - 2,27 (IGNTP) Hk $\mathrm{Hk}^{\mathrm{txt}} \varepsilon 1 \sigma \alpha \gamma \alpha \gamma \varepsilon \iota v, \mathrm{Hk}^{\mathrm{mg}}$ $\varepsilon 1 \sigma \alpha \gamma \varepsilon 1 v$ (not in V267 D) - 2,43 (NA27) $\mathrm{Hk}^{\mathrm{xxt}} \varepsilon \gamma \nu \omega \mathrm{I} \omega \sigma \eta \phi \kappa \alpha \iota$ $\eta \mu \eta \tau \eta \rho, \mathrm{Hk}^{\mathrm{mg}} \varepsilon \gamma \nu \omega \sigma \alpha \nu$ or $\gamma \mathrm{ov \varepsilon \varepsilon} \varsigma$ (not in $\mathbf{M}$ ) - 5,7 (NA $\left.{ }^{27}\right) \mathrm{Hk}^{\mathrm{txt}}$ $\omega \sigma \tau \varepsilon \beta \nu \theta \imath \zeta \varepsilon \sigma \theta \alpha \imath \alpha v \tau \alpha, \mathrm{Hk}^{\mathrm{mg}} \mathrm{ADD}$. $\pi \alpha \rho \alpha \tau \imath$ after $\omega \sigma \tau \varepsilon$ (not in

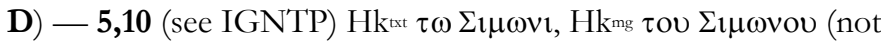
in MD) - 5,21 (IGNTP) Hk $\mathrm{Hk}^{\mathrm{xxt}} \mu \mathrm{vos}, \mathrm{Hk}^{\mathrm{mg}} \varepsilon v o \varsigma$ (not in D) 6,48 (NA $\left.{ }^{27}\right) \mathrm{Hk}^{\mathrm{txt}} \tau \varepsilon \theta \varepsilon \mu \varepsilon \lambda \iota \omega \tau \mathrm{o} \gamma \alpha \rho \varepsilon \pi \mathrm{\imath} \tau \eta \nu \pi \varepsilon \tau \rho \alpha \nu$, Hk $\mathrm{k}^{\mathrm{mg}} \delta 1 \alpha$

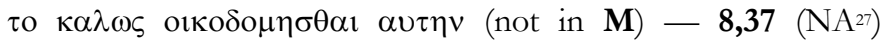

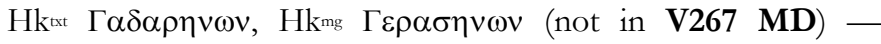
8,38 (NA $\left.^{27}\right) \mathrm{Hk}^{\mathrm{txt}} \alpha \pi \varepsilon \lambda \nu \sigma \varepsilon v, \mathrm{Hk}^{\mathrm{mg}} \alpha \pi \varepsilon \sigma \tau \varepsilon 1 \lambda \varepsilon v$ (not in MD) -

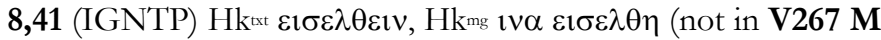

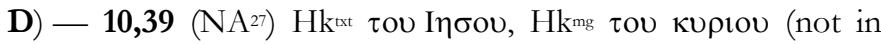
D) - 11,13 $\left(\mathrm{NA}^{27}\right) \mathrm{Hk}^{\mathrm{txt}} \alpha \gamma \mathrm{\gamma lov}$, Hk ${ }^{\mathrm{mg}} \alpha \gamma \alpha \theta$ ov (not in $\mathbf{D}$ ) - 12,1

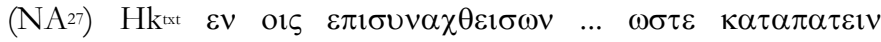

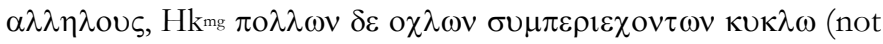
in V267 D) - 13,3 (NA27) Hk ${ }^{\mathrm{txt}} \omega \sigma \alpha v \tau \omega \varsigma, \mathrm{Hk}^{\mathrm{mg}}$ o $\mu \mathrm{ol} \omega \varsigma$ (not in V267 D) - 13,15 (NA $\left.{ }^{27}\right) \mathrm{Hk}^{\mathrm{xxt}} \mathrm{v}$ ч V267 M D) - 13,31 (NA $\left.{ }^{27}\right) \mathrm{Hk}^{\mathrm{xxt}} \eta \mu \varepsilon \rho \alpha$, Hk ${ }^{\mathrm{mg}} \omega \rho \alpha$ (not

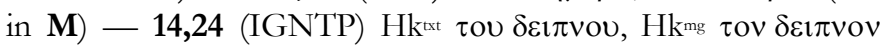

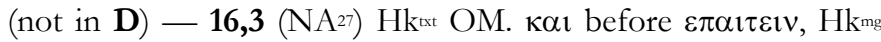
ADD. $\kappa \alpha \iota$ before $\varepsilon \pi \alpha \imath \tau \varepsilon \imath$ (not in V267) - 19,8 (IGNTP) Hk kupiov, Hkmg Inoouv (not in D) - 20,13 (NA27) Hk ${ }^{\text {rxt }}$ ADD.

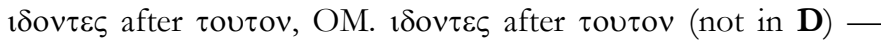




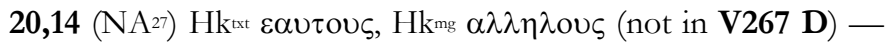
22,34 (NA27) Hk ${ }^{\mathrm{xt}} \pi \rho v v \eta, \mathrm{Hk}^{\mathrm{mg}} \varepsilon \omega \varsigma$ (not in $\left.\mathbf{M}\right)-22,36$ (NA27) Hkt $\varepsilon 1 \pi \varepsilon v$ ouv, Hkm o $\delta \varepsilon \varepsilon 1 \pi \varepsilon v$ (not in $\mathbf{M}$ ) - 22,37 $\mathrm{Hk}^{\mathrm{m}}$ $\tau \alpha \pi \varepsilon \rho \imath \varepsilon \mu o v$, Hkmg $\tau$ o $\pi \varepsilon \rho \imath \varepsilon \mu \circ v$ (not in $\mathbf{D})$. - 22,49 (NA ${ }^{27}$ ) Hkt $\varepsilon \sigma o \mu \varepsilon v o v, \mathrm{Hk}^{\mathrm{mg}} \gamma \varepsilon v o \mu \varepsilon v \mathrm{v}$ (not in $\left.\mathbf{M}\right)-\mathbf{2 2 , 6 6}\left(\mathrm{NA}^{27}\right.$ ) $\mathrm{Hk}^{\mathrm{kxt}}$

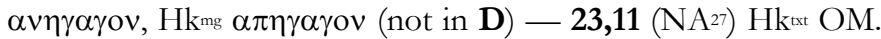

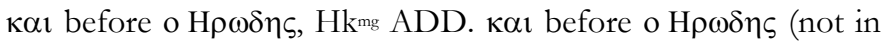
M D) - 23,12 (IGNTP) Hk ${ }^{\times t} \eta \mu \varepsilon \rho \alpha, \mathrm{Hk}^{\mathrm{mg}} \omega \rho \alpha$ (not in M).

- Again the opposite case that the Byzantine reading is in the Harklean margin we find only in 2,17 (IGNTP) Hkøt $\varepsilon \gamma v \omega \rho ı \sigma \alpha v$, $\mathrm{Hk}^{\mathrm{mg}} \delta i \varepsilon \gamma v \omega \rho i \sigma \alpha v$ (not in $\left.\mathbf{M}\right)-4,44\left(\mathrm{NA}^{27}\right) \mathrm{Hk}^{\mathrm{x} t} \ldots$ in

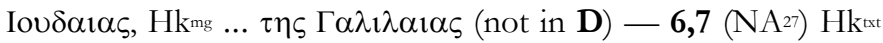

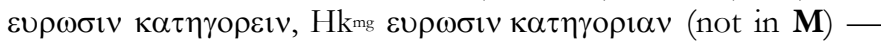

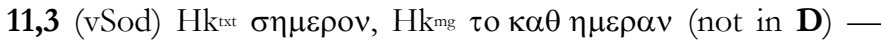
14,22 (IGNTP) Hk ${ }^{\text {st }} \gamma \varepsilon \gamma \mathrm{ov} \varepsilon v \omega \xi$, Hkmg $\gamma \varepsilon \gamma \mathrm{ov} \varepsilon v$ o (not in $\mathbf{M} \mathbf{D}$ ) -

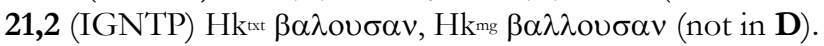

- Some marginal readings are also unhomogeneously attested by the Harklean manuscripts, but their Greek background cannot be traced with the help of the current Greek editions: 1,38 $(\mathrm{R})$

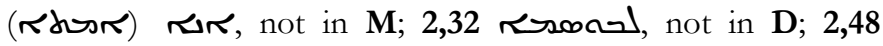
רحירז, not in M D; 2,52 Rata, not in M; 3,14 rif

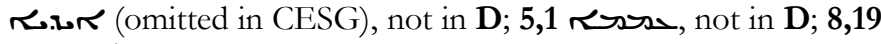
$\rightarrow$ asd, not in $\mathbf{D}$.

\section{List C}

[14] List $C$ presents the revisional alteration of the non-Byzantine textline in Ms V268 (no margin is attached throughout). The other three manuscripts omit its reading or put it in the margin. All these alterations are corrections of the textline in V268 according to the Byzantine text, and the additional marginalia are due to the revisor(s), not to Thomas. It seems to be quite obvious that here V268 represents an earlier stage of the Harklean text than the other three (four) manuscripts. What is most striking is the fact that V268 alone preserves these readings, and even the Florentine manuscript (one of the oldest at all, A.D. 756), gives the revised reading in the textline. But the generally poor attestation of the Harklean margin in only a few manuscripts of the first millennium tells us to be careful. The same are pointing to the few nonByzantine readings which remained unrevised in all Harklean 
manuscripts used for this article. Some of them were removed to the margin only in later times, as we can learn from Ms New Coll. 333 (White' edition) (samples see below). And even some Byzantine readings are removed to the margin by the reviser(s) (see below). Both phenomena can be explained by the unhomogeneity of the Byzantine text the reviser(s) had at hand.

Readings of V268 are removed from the text to the margin in V267, $\mathbf{D}$ or $\mathbf{M}$ (the underlined readings are in opposition to the quotation of White's text and margin in NA27/Syn, they are good samples for the need to revise the Harklean quotations in the scholarly Greek editions of the New Testament):

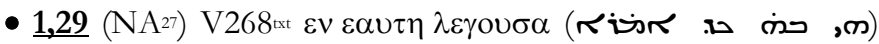
$\mathbf{M} \mathbf{D}$ put in the margin, V267 eliminates without margin, $\mathbf{F}$ is omitting. The omission is the Byzantine reading.

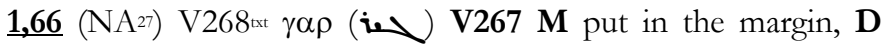
omits in without $\mu \alpha p \gamma i v$. The omission of it is the Byzantine reading.

3,16 (NA27) V268 ${ }^{\text {xt }} \varepsilon 15 \mu \varepsilon \tau \alpha v o l \alpha v$ (Rhone $\downarrow$ ) V267 D have in the margin, not in the text, $\mathbf{F}$ is omitting ( $\mathbf{M}$ is supplemented here). The opıббıv $1 \sigma \tau \eta \varepsilon$ B $\psi \zeta \alpha \nu \tau \imath v \varepsilon \rho \varepsilon \alpha \delta i v \gamma$.

4,9 (in no edition) V268 margin, V267 $\mathbf{D}$ remove it from the text without margin, $\mathbf{F}$ is

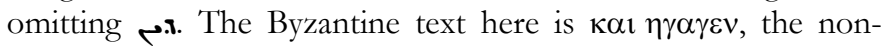
Byzantine text reads $\eta \gamma \alpha \gamma \varepsilon v \delta \varepsilon$. Removing $\mathrm{x}$ from the textline means to follow the Byzantine text. The reading of V268 V267 xxt with a and $\mathrm{x}$ is unusual and not attested in Greek.

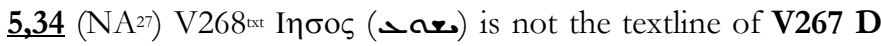
and $\mathbf{F}$, and only $\mathbf{V} 267$ has it in the margin (again $\mathbf{M}$ is supplemented here). The omission is the Byzantine reading.

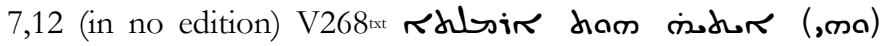

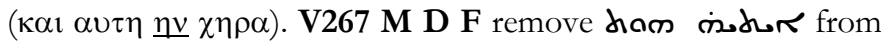
the text, V267 M D put it in the margin, probably because the Byzantine text leaves it out ( $\kappa \alpha \iota \nu \tau \tau \eta \chi \eta \rho \alpha)$.

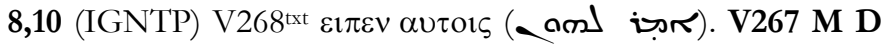

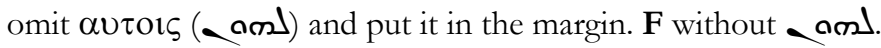
The omission belongs to the Byzantine text.

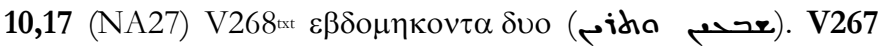
M D remove $\delta v o$ (pida) to the margin, $\mathbf{F}$ without pita. Their textline is the Byzantine reading. 


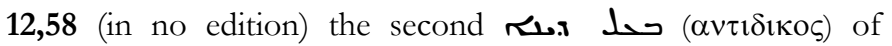
V268xt is in the margin of V267 M D (and omitted in the text of F), probably because the 'normal' Greek text does not attest this

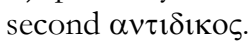

14,15 (NA27) V268

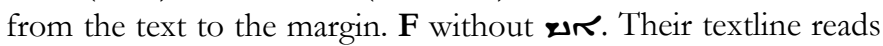
os $(\mathrm{am})$, which is the Byzantine reading.

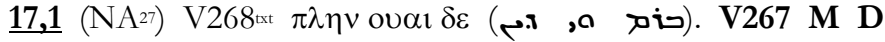
remove حiv from the text to the margin. $\mathbf{F}$ without textline now is $, \boldsymbol{x}, \mathrm{a}$, which is the Byzantine reading.

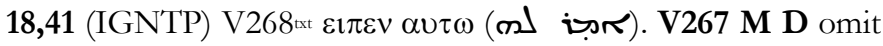
$\alpha \cup \tau \omega$ ( $\infty)$, only V267 puts it in the margin. F without $m$. The omission is the Byzantine text.

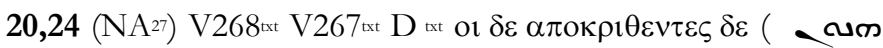

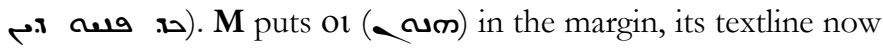
is without cum.

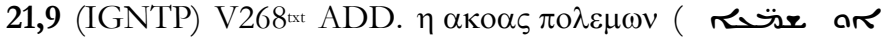

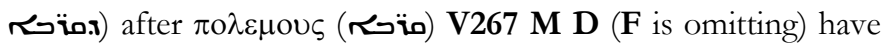
it in the margin. The text without addition is the Byzantine one.

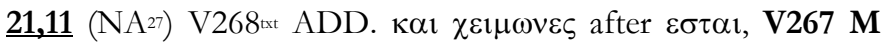
put it in the margin, $\mathbf{F}$ is omitting. $\mathbf{D}$ has no margin, but its

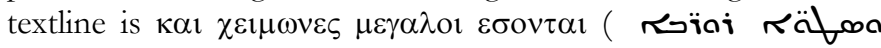
anms), not attested in Greek. The Byzantine text has no addition.

- There are few Byzantine readings in the textline of V268 which are removed to the margin in V267, $\mathbf{D}$ or $\mathbf{M}$ :

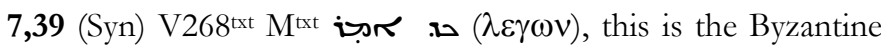
text. V267 D F remove حמ. רדיi from the textline, only V267 puts it in the margin.

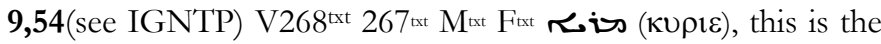
Byzantine text. $\mathbf{D}$ removes it from the text to the margin.

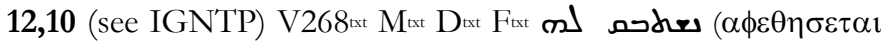
$\alpha \cup \tau \omega)$, this is the Byzantine text. V267 puts $\alpha \nu \tau \omega$ ( $)$ ( ) in the margin.

- In all Harklean manuscripts (including $\mathbf{F}$ ) used for this article non-Byzantine readings remained in the textline, which later were removed to the margin or were omitted without being put in the 
margin, e.g. in Ms New Coll. 333 (ed. by J. White = NC333). Three samples are:

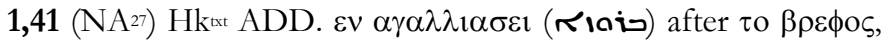
NC333 removes it to the margin to follow the 'normal' (Byzantine) text.

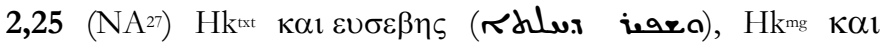
$\varepsilon v \lambda \alpha \beta \eta \varsigma$ (حصح

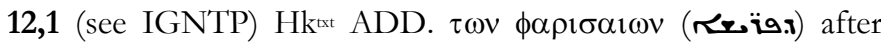

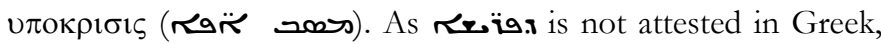
V267 M D put it sub asterisco, NC333 removes it from the text without preserving it in the margin.

[16] Beside these marginalia due to revision V267, $\mathbf{M}$ and $\mathbf{D}$ have no additional readings in the margin which are not attested by V268. But on the contrary it is V268 which presents some marginalia not to be found in the other three manuscripts (see note 14). The poor attestation of the Harklean apparatus in general will prevent us from over-esteeming this surplus, but the view that V268 is at an earlier stage of revision than V267, $\mathbf{M}$ and $\mathbf{D}$ (and F) can hardly be wrong. The revisional development is moving from V268 to the other three manuscripts, not the contrary.

\section{SUMMARY}

The Harklean Tetraevangelium is principally founded upon the Byzantine text, but Ms Vat. syr 268 has maintained a larger number of non-Byzantine readings in text and margin than the other three manuscripts. The differences between V268 and the other three can be explained by revisional development to bring the Harklean text of V268 into better line with the Byzantine text. On the one hand this development results in omitting marginalia which cannot be identified within the 'normal' Greek text; on the other hand, this development results in adding new marginalia by removing the reading of the textline. The conclusion drawn from the evidence presented in this article is that text and margin of V268 are prior to the ones of V267, $\mathbf{M}$ and $\mathbf{D}$, and that the oldest Harklean text of the Gospels we can reach today is that of V268. Both the number of its non-Byzantine text readings and of the marginal notes in general is larger than in any other Harklean manuscript of the first millennium. A critical edition of the Harklean Tetraevengelium 
should give priority to this manuscript as long as no less revised manuscripts of the first millennium are known. But keeping the limitations of this article in mind, research on the critical signs (asterisks and obeli) and on translation technique must re-examine and complete the results presented here. 
